\title{
Regional Proteomic Quantification of Clinically Relevant Non-Cytochrome P450 Enzymes along the Human Small Intestine ${ }^{\text {⿷ }}$
}

\author{
Haeyoung Zhang, Chris Wolford, ๑Abdul Basit, Albert P. Li, Peter W. Fan, Bernard P. Murray,
} Ryan H. Takahashi, S. Cyrus Khojasteh, Bill J. Smith, Kenneth E. Thummel, and Bhagwat Prasad

\begin{abstract}
Department of Pharmaceutics, University of Washington, Seattle, Washington (H.Z., C.W., A.B., K.E.T., B.P.); Department of Pharmaceutical Sciences, Washington State University, Spokane, Washington (A.B., B.P.); In Vitro ADMET Laboratories Inc., Columbia, Maryland (A.P.L.); Department of Pharmacokinetics, Pharmacodynamics and Drug Metabolism, Merck \& Co., Inc., Boston, Massachusetts (P.W.F.); Genentech Inc., South San Francisco, California (R.H.T., S.C.K.); and Drug Metabolism Department, Gilead Sciences Inc., Foster City, California (B.J.S., B.P.M.)
\end{abstract}

Received February 10, 2020; accepted March 18, 2020

\begin{abstract}
Current challenges in accurately predicting intestinal metabolism arise from the complex nature of the intestine, leading to limited applicability of available in vitro tools as well as knowledge deficits in intestinal physiology, including enzyme abundance. In particular, information on regional enzyme abundance along the small intestine is lacking, especially for non-cytochrome P450 enzymes such as carboxylesterases (CESs), UDP-glucuronosyltransferases (UGTs), and sulfotransferases (SULTs). We used cryopreserved human intestinal mucosa samples from nine donors as an in vitro surrogate model for the small intestine and performed liquid chromatography tandem mass spectrometry-based quantitative proteomics for 17 non-cytochrome P450 enzymes using stable isotope-labeled peptides. Relative protein quantification was done by normalization with enterocyte marker proteins, i.e., villin-1, sucrase isomaltase, and fatty acid binding protein 2 , and absolute protein quantification is reported as picomoles per milligram of protein. Activity assays in glucuronidations and sequential metabolisms were conducted to
\end{abstract}

validate the proteomics findings. Relative or absolute quantifications are reported for CES1, CES2, five UGTs, and four SULTs along the small intestine: duodenum, jejunum, and ileum for six donors and in 10 segments along the entire small intestine $(A-J)$ for three donors. Relative quantification using marker proteins may be beneficial in further controlling for technical variabilities. Absolute quantification data will allow for scaling factor generation and in vivo extrapolation of intestinal clearance using physiologically based pharmacokinetic modeling.

\section{SIGNIFICANCE STATEMENT}

Current knowledge gaps exist in intestinal protein abundance of non-cytochrome P450 enzymes. Here, we employ quantitative proteomics to measure non-cytochrome P450 enzymes along the human small intestine in nine donors using cryopreserved human intestinal mucosa samples. Absolute and relative abundances reported here will allow better scaling of intestinal clearance.

\section{Introduction}

Oral intake is the most common route of drug administration because of its convenience and cost-effectiveness (Deng et al., 2017). However, incomplete and variable bioavailability can arise from oral administration, as drugs pass through barriers in absorption, intestinal metabolism, and hepatic metabolism before reaching systemic circulation (Thummel, 2007). Notably, these are sequential events with multiplicative effects that can significantly reduce systemic drug

This work was supported by the Proteomics-based Research Initiative for Non-CYP Enzymes (PRINCE) consortium and University of Washington Department of Pharmaceutics.

Conflicts of interest: CHIM is a commercial product of In Vitro ADMET Laboratories Inc.

https://doi.org/10.1124/dmd.120.090738.

S This article has supplemental material available at dmd.aspetjournals.org. exposure, potentially limiting drug efficacy and increasing interpatient variability in drug response. Historically, intestinal metabolism was considered to be of minor importance compared with the liver because of a smaller tissue mass containing drug-metabolizing enzymes (DMEs) (Thummel, 2007). However, a significant impact of intestinal DMEs on systemic drug exposure has been demonstrated for substrates of CYP3A4, such as cyclosporine (Kolars et al., 1991), midazolam (Paine et al., 1996), and cobimetinib (Takahashi et al., 2016), as well as substrates for intestinal sulfotransferases (SULTs) and UDP-glucuronosyltransferases (UGTs) such as acetaminophen, phenylephrine, terbutaline, and raloxifene (Shen et al., 1997; Wu et al., 2011). Further, clinically significant food-drug interactions can occur at the intestine. For example, inhibition of CYP3A4 by furanocoumarins in grapefruit juice giving rise to altered systemic exposure of drugs has been shown in vivo, resulting in labeling changes for several medications (Bailey et al., 2013).

ABBREVIATIONS: ABC, amonium bicarbonate; BSA, bovine serum albumin; CAG, clopidogrel acyl glucuronide; CCA, clopidogrel carboxylic acid; CERM, Cryopreserved Enterocyte Recovery Medium; CES, carboxylesterase; CHIM, cryopreserved human intestinal mucosa; CPG, clopidogrel; CPT-11, camptothecin-11; DME, drug-metabolizing enzyme; FABP2, fatty acid binding protein 2; HQM, Hepatocyte/Enterocyte Incubation Medium; LC-MS/MS, liquid chromatography tandem mass spectrometry; M/P ratio, metabolite-to-parent ratio; PBPK, physiologically based pharmacokinetic; PQC, positive quality control; SI, sucrase isomaltase; SIL, stable isotope-labeled; SULT, sulfotransferases; TG, testosterone glucuronide; UGT, UDP-glucuronosyltransferase; VIL1, villin-1. 
A major limitation in investigating intestinal metabolism is the lack of reproducibility in available in vitro systems (Peters et al., 2016; Rostami-Hodjegan et al., 2017). This is in stark contrast to well established in vitro tools available for studying hepatic metabolism, including subcellular fractions such as microsomes, and primary human hepatocytes, which are considered to be the gold standard (Li et al., 2018). The region of the intestine used for in vitro preparations can differ widely, as can the preparation techniques for tissue fractionation and isolation of intestinal subcellular fractions, leading to inconsistent quality of preparations, which may impact scaling factors (Hatley et al., 2017a,b). Moreover, the commonly used colon cancer Caco-2 cell line, although useful for studying absorption, has low baseline expression of most DMEs, limiting its use in intestinal metabolism assessment (Küblbeck et al., 2016). Exploration of other immortalized cell lines (LS180, T84), fetal human small intestinal epithelial cells, and stem cell-derived enterocytes have failed to fully replicate in vivo intestinal metabolism (Yamaura et al., 2016). Human precision-cut intestinal slices, although most biologically representative, do not offer long-term viability or preservation for widespread and reproducible use (Li et al., 2016). Primary human enterocytes show promising activity (Ho et al., 2017), but isolation may also be more sensitive to the method employed because of the heterogeneous nature of the small intestine compared with the liver (Hatley et al., 2017b; Li et al., 2018). Intestinal three-dimensional organoid cultures have shown to be useful for investigating disease states, but their utility in drug development has not been thoroughly evaluated. Regardless of the metabolic system, knowledge deficits in enzyme abundance and resulting lack of scaling factors are major limitations of intestinal in vitro tools, which are further hampered in preclinical animal models because of interspecies differences (Peters et al., 2016).

Physiologically based pharmacokinetic (PBPK) modeling has been proposed as an important tool to address the complexities of intestinal metabolism (Peters et al., 2016). PBPK modeling is also recognized by regulatory agencies as a useful tool that combines system-specific physiology and drug-specific properties to help guide labeling decisions for certain conditions or populations (Yeo et al., 2013; Jamei, 2016). In a recent effort to assess PBPK applications of orally administered drugs, large discrepancies were noted between measured and simulated profiles, with an indication of knowledge gaps in intestinal physiologic system (Darwich et al., 2017; Margolskee et al., 2017a,b). Quantitative proteomics applied to different tissues can generate the scaling factors necessary for mechanistic modeling approaches and lessen the knowledge gap (Prasad et al., 2017). Although intestinal abundance of cytochrome P450s is well described in the literature (Paine et al., 2006), studies of non-cytochrome P450 DMEs including UGTs are generally lacking (Gufford et al., 2014). As an example, UGT2B17 is an understudied intestinal isoform harboring a common gene deletion and high interindividual variability (Zhang et al., 2018).

We used cryopreserved human intestinal mucosal epithelium (CHIM) as a surrogate model for proteomic quantification of metabolically active intestinal tissue. CHIM is a novel in vitro tool for evaluating intestinal metabolism and is prepared using collagenase digestion to separate the mucosa from underlying muscularis and serosal tissue, followed by gentle homogenization of the mucosa and cryopreservation (Li et al., 2018). Minimal processing of CHIMs aims to retain the heterogeneous cellular nature of the intestinal mucosa (primarily epithelia) and high level of DME expression, thus allowing a more functionally representative experimental system ( $\mathrm{Li}$ et al., 2018). Proteomic characterization of such tissue is necessary to generate scaling factors for in vitro-to-in vivo extrapolations and further translation and application of the CHIM model (Rostami-Hodjegan, 2012).
Heterogeneity of the small intestine necessitates additional considerations for proteomic characterization. In particular, incorporation of marker proteins, which are specific for mature enterocytes, is needed for accurate scaling. Several specific markers for enterocytes have been reported. Villin-1 (VIL1) is an actin-binding protein that is a major structural constituent of enterocyte brush borders and microvilli, with high levels found in mature differentiated cells (Hodin et al., 1997). Sucrase isomaltase (SI) is reported to be a specific marker for intestinal epithelial cells (Iwao et al., 2014). Intestinal fatty acid binding protein 2 (FABP2) is a cytosolic protein that is specific for mature enterocytes (Piton and Capellier, 2016).

Here, we report proteomic characterization of non-cytochrome P450 enzymes known or suspected to be expressed along the length of the human small intestine in CHIMs using LC-MS/MS quantitative proteomics with stable isotope-labeled (SIL) peptides. The following 17 enzymes were examined: aldehyde oxidase, carboxylesterase 1 (CES1), CES2, UGT1A1, UGT1A3, UGT1A4, UGT1A6, UGT1A8, UGT1A10, UGT2B4, UGT2B7, UGT2B17, sulfotransferase 1A1 (SULT1A1), SULT1A3, SULT1B1, and SULT2A1. We compared the non-cytochrome $\mathrm{P} 450$ abundance in CHIM with a commercially available pooled intestinal S9 (GIS9) fraction and compared the proteomic findings with $\mathrm{CHIM}$ activity assays. We investigated testosterone glucuronidation as a UGT2B17-specific probe reaction and UGT2Bmediated clopidogrel acyl glucuronide (CAG) formation using clopidogrel carboxylic acid (CCA) as a substrate and imatinib as a UGT2B17-specific inhibitor. Additionally, we qualitatively examined sequential metabolism using clopidogrel (CPG) and camptothecin-11 (CPT-11) as substrates for CES1 and CES2, respectively, with subsequent glucuronidation reactions mediated by UGT2Bs and UGT1A1, respectively.

\section{Materials and Methods}

Materials. SIL peptides and synthetic unlabeled peptides were purchased from Thermo Fisher Scientific (Rockford, IL) and New England Peptides (Boston, MA), respectively. Ammonium bicarbonate (ABC, 98\% purity), bovine serum albumin (BSA), dithiothreitol, iodoacetamide, trypsin protease (mass spectrometry grade), testosterone, and CPT-11 were obtained from Thermo Fisher Scientific. Clopidogrel, clopidogrel carboxylic acid, and clopidogrel acyl glucuronide were ordered from Toronto Research Chemicals (North York, $\mathrm{ON}$ ), and testosterone glucuronide- $\mathrm{d} 3$ was obtained from Cerilliant Corporation (Round Rock, TX). Human serum albumin was acquired from Calbiochem (Billerica, MA). Mem-PER Plus Membrane Protein Extraction kit, Pierce bicinchoninic acid protein assay kit, Optima MS-grade acetonitrile, chloroform, methanol, and formic acid were purchased from Fisher Scientific (Fair Lawn, NJ). Pooled GIS9 fractions were purchased from Xenotech (Kansas City, KS). CHIM samples, Cryopreserved Enterocyte Recovery Medium (CERM), and Hepatocyte/ Enterocyte Incubation Medium (HQM) were purchased from In Vitro ADMET Laboratories, Inc (Columbia, MD). Segmented sections (A-J) were dissected in 12-inch increments from the pyloric sphincter. CHIM donor demographics are shown in Table 1.

Protein Extraction. Protein extraction was performed using the Mem-PER Plus Membrane Protein Extraction kit (Thermo Fisher Scientific), closely following a previously published protocol (Zhang et al., 2018). CHIM samples were thawed in a $37^{\circ} \mathrm{C}$ water bath for $90-120$ seconds, then resuspended in MemPER kit cell wash solution or recovery media (CERM), followed by centrifugation at $300 \mathrm{~g}$ for 5 minutes or $100 \mathrm{~g}$ for 10 minutes at room temperature, respectively, and supernatants were removed. This wash process was performed twice with cell wash solution. Samples washed with CERM underwent an additional resuspension in HQM and centrifugation at $300 \mathrm{~g}$ for 5 minutes at $4{ }^{\circ} \mathrm{C}$. CHIMs were then resuspended in 110-500 $\mu 1$ of permeabilization buffer and placed on an Eppendorf ThermoMixer (Hauppauge, NY) with shaking at $300 \mathrm{rpm}$ for 30 minutes at $4^{\circ} \mathrm{C}$. Permeabilized cells were then centrifuged at $16,000 \mathrm{~g}$ for 15 minutes at $4^{\circ} \mathrm{C}$, and resulting supernatant containing cytosolic proteins was collected. Remaining pellets were resuspended in 110-500 $\mu$ l of solubilization buffer, sonicated for 30 seconds, and incubated with shaking at $300 \mathrm{rpm}$ for 
TABLE 1

CHIM demographics

\begin{tabular}{|c|c|c|c|c|}
\hline Donor ID & $\begin{array}{l}\text { Age } \\
\text { (yr) }\end{array}$ & Sex & Race & Available Intestinal Segment \\
\hline 6023 & 49 & $\mathrm{~F}$ & Caucasian & $\mathrm{A}$ and $\mathrm{B}, \mathrm{D}-\mathrm{J}(n=9)$ \\
\hline 6037 & 59 & $\mathrm{~F}$ & Pacific Islander & $\mathrm{A}-\mathrm{J}(n=10)$ \\
\hline 6038 & 38 & M & Caucasian & $\mathrm{A}-\mathrm{J}(n=10)$ \\
\hline 6001/03/05 (1) & 20 & M & Caucasian & Duodenum, jejunum, ileum \\
\hline 6008/07/06 (2) & 20 & M & Caucasian & Duodenum, jejunum, ileum \\
\hline $6012 / 11(3)$ & 36 & $\mathrm{~F}$ & Asian & Duodenum, jejunum \\
\hline $6015 / 10 / 16(4)$ & 59 & M & Caucasian & Duodenum, jejunum, ileum \\
\hline $6018 / 17 / 19(5)$ & 57 & $\mathrm{~F}$ & Caucasian & Duodenum, jejunum, ileum \\
\hline HE3061/64/48 (6) & 59 & M & Hispanic & Duodenum, jejunum, ileum \\
\hline
\end{tabular}

F, female; ID, identifier; M, male.

60 minutes at $4^{\circ} \mathrm{C}$. Total protein concentrations were measured from protein extraction aliquots using Pierce bicinchoninic acid protein assay according to the manufacturer's protocol, using BSA as the calibrator protein (Thermo Fisher Scientific). Samples were standardized for protein digestion to 2 and $0.5 \mathrm{mg} / \mathrm{ml}$ with the addition of solubilization and permeabilization buffer for membrane and cytosolic proteins, respectively. All samples were stored at $-80^{\circ} \mathrm{C}$ until further analysis.

Protein Denaturation, Alkylation, Enrichment, and Digestion. Trypsin digestion followed previously described optimized protocols (Bhatt et al., 2019). Extracted protein aliquots were mixed with $\mathrm{ABC}$ buffer $(100 \mathrm{mM}, \mathrm{pH} \mathrm{7.8)}$, dithiothreitol $(250 \mathrm{mM})$, BSA $(0.02 \mathrm{mg} / \mathrm{ml})$, and human serum albumin $(10 \mathrm{mg} / \mathrm{ml})$ and then denatured for 10 minutes at $95^{\circ} \mathrm{C}$. Upon cooling, iodoacetamide (500 $\mathrm{mM}$ ) was added for alkylation of cysteine residues, followed by incubation in the dark at room temperature for 30 minutes. Protein enrichment and desalting were done with the addition of chloroform-methanol-water $(1: 5: 4)$, followed by removal of the liquid phase under vacuum, pellet wash with methanol, drying, and resuspension with $\mathrm{ABC}$ buffer $(50 \mathrm{mM}, \mathrm{pH} 7.8)$. Protein digestion was initiated with the addition of trypsin $(0.16 \mu \mathrm{g} / \mu \mathrm{l})$ and incubated for 16 hours with shaking at $300 \mathrm{rpm}$ at $37^{\circ} \mathrm{C}$. Digestion was stopped with the addition of ice-cold acetonitrile: water $80: 20(\mathrm{v} / \mathrm{v})$ with $0.5 \%$ formic acid and SIL internal standard cocktail. A minimum of five positive quality controls (PQCs) and three pooled GIS9 fractions were included in each batch of processed samples to assess robustness and reproducibility and control for technical and instrumental variability.

Quantification of Surrogate Peptides of Non-Cytochrome P450 DMEs. Samples were analyzed using an Acquity ultra-performance liquid chromatography system (Waters, Milford, MA) coupled to a Sciex Triple Quadrupole 6500 system (Sciex, Framingham, MA). An Acquity ultra-performance liquid chromatography HSS T3 $1.8 \mu \mathrm{m}, \mathrm{C}_{18} 100 \AA$; $100 \times 2.1 \mathrm{~mm}$ column (Waters) was used to achieve chromatographic peptide separation following previously established protocols (Bhatt, et al., 2019). Skyline software (University of Washington, Seattle, WA) was used to process acquired data. Representative LCMS/MS chromatograms are provided (Supplemental Fig. 1).

Both absolute and relative quantifications were performed. Absolute abundance data are presented as picomoles protein per milligram of membrane or cytosolic protein. Samples with total protein concentrations falling below the optimized digestion concentration were excluded from analysis. Relative abundance was calculated as peak area ratio normalized with average peak area ratio of villin-1 and sucrase isomaltase for membrane proteins and fatty acid binding protein 2 for cytosolic proteins. Relative quantification was done to address technical variability associated with CHIM preparations and the multicellular nature of intestinal tissue. Relative quantification was performed for 11 DMEs and all marker proteins: CES1, CES2, UGT1A1, UGT1A3, UGT1A10, UGT2B7, UGT2B17, SULT1A1, SULT1A3, SULT1B1, SULT2A1, and VIL1, SI, and FABP2. Relative quantification was also done for subcellular marker proteins such as calnexin and calreticulin as endoplasmic reticulum membrane and lumen markers, respectively. Absolute quantification was performed utilizing a PQC sample as a calibrator from our previous studies for all proteins listed above except SULT1A3, SULT1B1, and marker proteins (Bhatt and Prasad, 2018). A previously optimized approach was applied for surrogate peptide selection and quantification for SULT1A3, SULT1B1, and marker proteins (Vrana et al., 2017). A list of studied proteins and their UniProt identifiers is provided (Supplemental Table 1). An optimized quantitative proteomics protocol was used to ensure the rigor and reproducibility (Bhatt and Prasad, 2018). Detailed LC-MS/MS parameters specific to this study are provided (Supplemental Table 2). The in silico peptide selection criteria ensures that the peptides are stable (Bhatt and Prasad, 2018). Autosampler stability of peptides has been tested by measuring consistency in the MS response of SIL peptides. Moreover, the PQC sample was stored at $-80^{\circ} \mathrm{C}$ and analyzed multiple times over a period of 1 year. The linearity and lower limit of quantification (LLOQ) were established with surrogate peptide standards (unlabeled peptides) for each enzyme in-house.

Activity Assays. CHIM samples were thawed in a $37^{\circ} \mathrm{C}$ water bath for up to 120 seconds. Samples were then resuspended in CERM and centrifuged at $100 \mathrm{~g}$ for 10 minutes at room temperature, followed by supernatant removal; this process was repeated with HQM. CHIM samples were then reconstituted with HQM to a protein concentration of $0.5 \mathrm{mg} / \mathrm{ml}$. In total, $50 \mu \mathrm{l}$ of CHIM suspension was added to 96 -well plates with $50 \mu$ l of HQM containing two times the desired final concentration of substrates, resulting in a final reaction volume of $100 \mu \mathrm{l}$. Substrates and final concentrations were as follows: testosterone $(5 \mu \mathrm{M}), \mathrm{CCA}$ $(100 \mu \mathrm{M}), \mathrm{CPG}(40 \mu \mathrm{M}), \mathrm{CPT}-11(20 \mu \mathrm{M})$, and imatinib $(5 \mu \mathrm{M})$. Upon addition of CHIM suspension and gentle mixing, plates were incubated for 30-60 minutes at $37^{\circ} \mathrm{C}$ and quenched with ice-cold acetonitrile containing internal standard testosterone glucuronide-d 3 . Plates were centrifuged at $300 \mathrm{~g}$ for 5 minutes at $4^{\circ} \mathrm{C}$, and 50- $\mu \mathrm{l}$ aliquots were transferred to corresponding LC-MS/MS compatible plates and stored at $-80^{\circ} \mathrm{C}$ until analysis. Detailed liquid chromatography gradient conditions and multiple reaction monitoring parameters are described (Supplemental Table 3). CAG quantification was done using an external calibration curve. Activity assays were performed based on protein content (milligrams of protein per milliliter), and correlation was examined with absolute protein quantification (picomoles per milligram protein).

Statistical Analysis. Statistical analysis was performed using Microsoft Excel (Redmond, WA) and GraphPad Prism version 5.03 for Windows (La Jolla, CA). Sectional comparisons (duodenum, jejunum, and ileum) were evaluated using nonparametric Kruskal-Wallis test, followed by Dunn's multiple comparison test. Segmented CHIM lots $(6023,6037,6038)$ were grouped into duodenum (A), jejunum $(\mathrm{B}-\mathrm{H})$, and ileum (I and J). Protein abundance-activity correlations were examined using the Spearman rank test. $P$ values less than 0.05 were considered significant.

\section{Results}

Non-Cytochrome P450 Enzyme Quantification. CESs and UGTs were quantified in CHIM membrane fractions, and SULTs were quantified in CHIM cytosolic fractions. Among the 17 proteins investigated, six proteins (i.e., aldehyde oxidase, UGT1A4, UGT1A6, UGT1A8, UGT2B4, and SULT1E1) were undetectable. UGT1A8, which is considered an intestinal selective UGT isoform, could not be detected, likely because of the low sensitivity for its surrogate peptide under the LC-MS/MS conditions employed. The surrogate peptides used for protein quantification were confirmed to be selective by multiple 

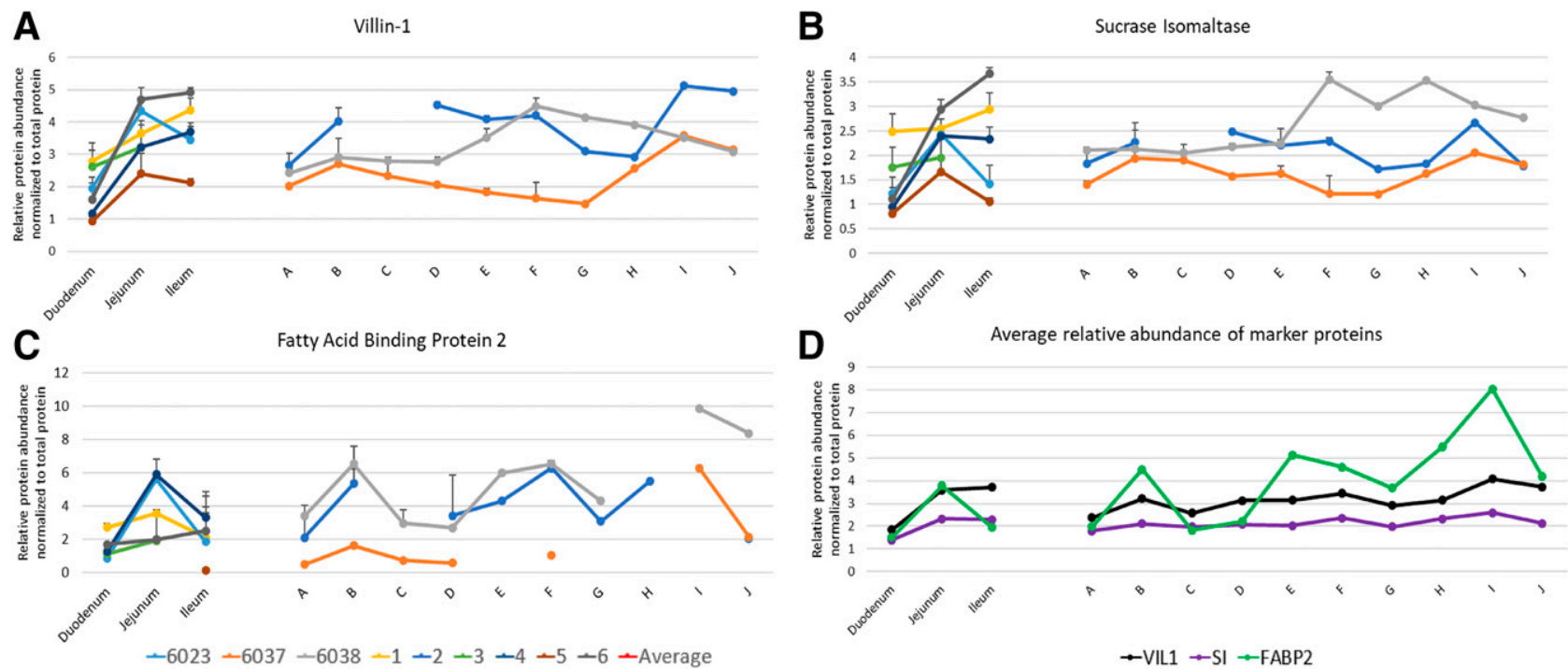

Fig. 1. Relative abundance of enterocyte marker proteins along the intestine. Relative area ratios for VIL1, SI, and FABP2 are normalized by total protein concentrations and are shown in (A-C). Average values for all marker proteins are shown in (D). The left panel in each figure shows CHIMs from duodenum, jejunum, and ileum in six donors. The right panel shows 10 segments down the intestinal tract (A-J) in three donors. Blank points indicate missing or excluded samples, and error bars show S.D.

approaches (i.e., in silico criteria, correlation of fragments and peptides, as well as coelution with SIL peptides) as discussed previously (Bhatt and Prasad, 2018). The variability in peptide response across multiple batches of PQC sample was within $20 \%$, which confirmed that the peptides and proteins are stable in the samples at $-80^{\circ} \mathrm{C}$ over a period of 1 year.

Relative Quantification of Non-Cytochrome P450 Enzymes Using Marker Proteins. Relative quantification for membrane enzymes was performed by normalization with average of SI and VIL1 and for cytosolic enzymes with intestinal FABP2. Regional distributions of relative area ratios normalized by total protein concentrations for VIL1, SI, FABP2, and their average values are shown in Fig. 1. There was a strong correlation between SI and VIL1 relative abundance, as well as significant correlations between SI and VIL1 average and FABP2, a cytosolic enterocyte marker. However, no correlation was seen with SI and VIL1 average and pan-UGT1A peptide, a peptide conserved across all UGT1A from shared exons (Supplemental Fig. 2). VIL1 and SI also showed significantly lower abundance in duodenum compared with the jejunum and ileum, whereas FABP2 distribution trended the same but remained nonsignificant (Supplemental Fig. 3). Relative quantifications for each enzyme are presented graphically in Fig. 2, compiled average values normalized to duodenum for all enzymes are shown in Fig. 3, and numerical values are reported (Supplemental Table 4). Relative DME abundance generally seemed to trend higher in duodenum compared with jejunum and further decreased in ileum because of the higherabundance of normalizing marker proteins. Segmented proteomic analyses across multiple sections $(n=10)$ indicate that interindividual variability was greater than interregional variability, indicated by the degree of nonoverlap between donors.

Absolute Quantification of Non-Cytochrome P450 Enzymes. Absolute quantifications are reported from membrane fractions (picomoles per milligram membrane protein) for CESs and UGTs and from cytosolic fractions (picomoles per milligram cytosolic protein) for SULTs. Table 2 shows the average values, and a graphical representation for each enzyme and compiled average values are presented (Supplemental Figs. 4 and 5, respectively). Absolute quantifications for cytosolic fractions in seven lots of CHIMs were excluded because of low total protein content (lots 6017, 6018, 6023-I, 6037-E, 6037-G, 6037-H, 6038-H). Absolute quantification showed higher variability and fluctuations between lots compared with relative quantification, possibly as an indicator of technical variability.

Comparison of CHIM Protein Quantification with Pooled Intestinal S9 Fraction. CHIM membrane and cytosolic protein fractions for non-cytochrome $\mathrm{P} 450$ enzymes and various marker proteins were compared with an independent pooled $(n=15)$ GIS9 fraction from Xenotech (Fig. 4). CESs and UGTs were undetectable in cytosolic fractions, whereas a majority of SULTs were present in cytosolic fractions, consistent with FABP2 recovery. SI is a brushborder enzyme and was enriched in the membrane fraction, whereas the cytoskeletal protein VIL1 was present in both fractions, but also with a strong significant correlation with SI (Supplemental Fig. 2). Calnexin and a pan-UGT1A conserved peptide as marker proteins for endoplasmic reticulum membrane showed enrichment in the membrane fraction. These data indicate that the DME protein abundance is not compromised in the CHIM samples. This comparison shows that relative levels of non-cytochrome P450 enzymes across two different models are consistent.

Glucuronide Formation and Sequential Metabolism in CHIM Model. To validate the utility of the CHIM model as a functional surrogate of intestinal tissue, non-cytochrome $\mathrm{P} 450$ functional activity assays were performed using four substrates, i.e., testosterone, CCA, CPG, and CPT-11. Testosterone glucuronide (TG) formation in the intestine is solely mediated by UGT2B17, whereas CAG formation from CCA is mainly catalyzed by UGT2B7 and UGT2B17, with minor contributions from UGT1A3 and UGT1A9 (Kahma et al., 2018). UGT2B17 CHIM protein abundance showed robust correlation with TG formation $\left(r^{2}=0.97, P=0.0004\right)$. CAG formation rate showed significant correlation with UGT2B17 abundance $\left(r^{2}=0.86, P=0.011\right)$ but not with UGT2B7 abundance $\left(r^{2}=0.33, \mathrm{~ns}\right)$, as shown in Fig. 5 . The correlation between CAG formation and UGT2B17 abundance became nonsignificant when imatinib, a UGT2B17-specific inhibitor, was coincubated with substrate. UGT1A3 and UGT1A10 abundance showed no significant correlation with CAG formation.

Sequential metabolism of CPG and CPT-11 by CES-mediated hydrolysis and UGT-mediated glucuronidation was examined using 
CES1
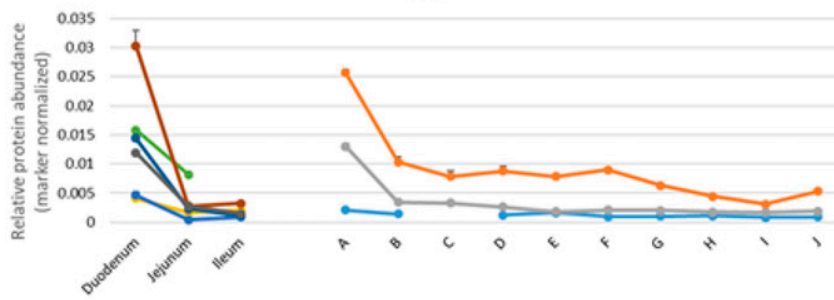

UGT1A1

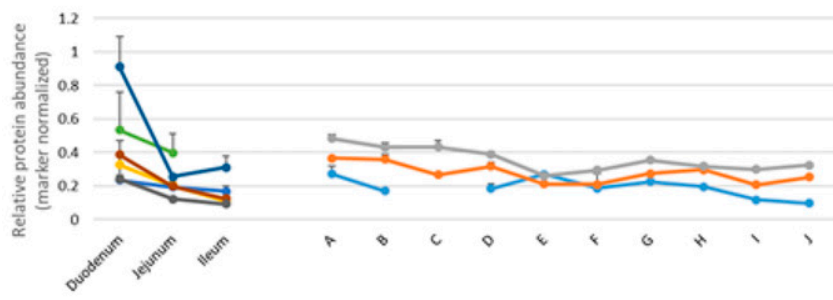

UGT1A10

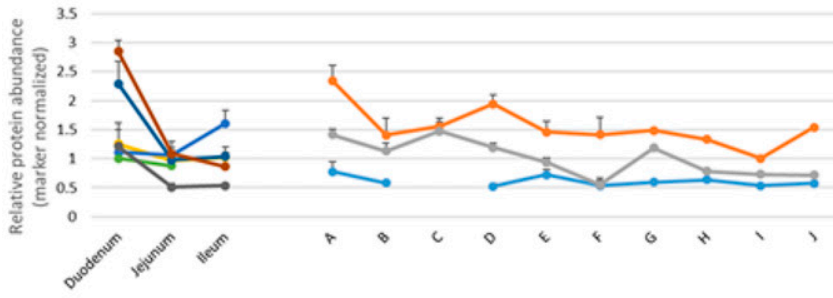

UGT2B17
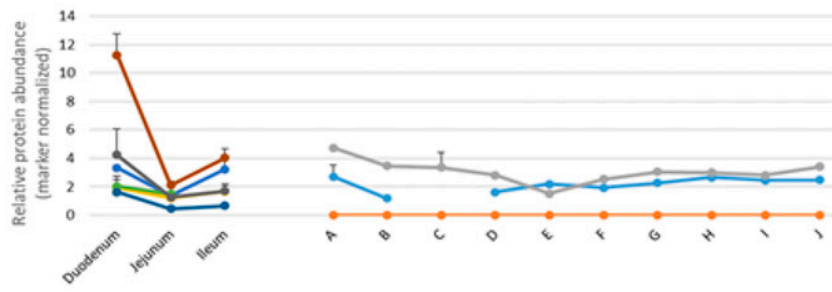

SULT1A3

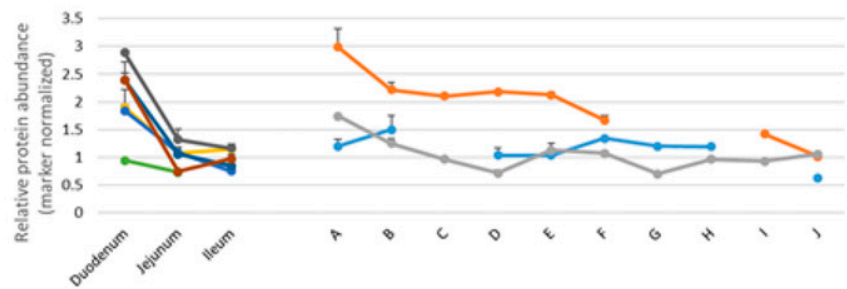

SULT2A1

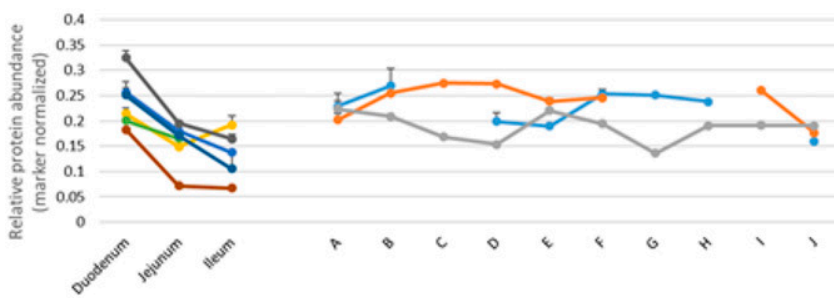

CES2

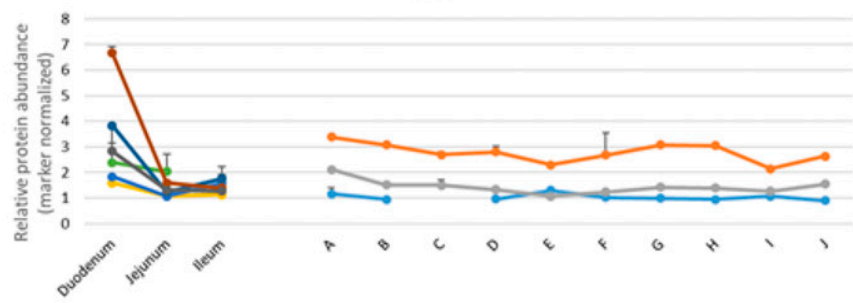

UGT1A3

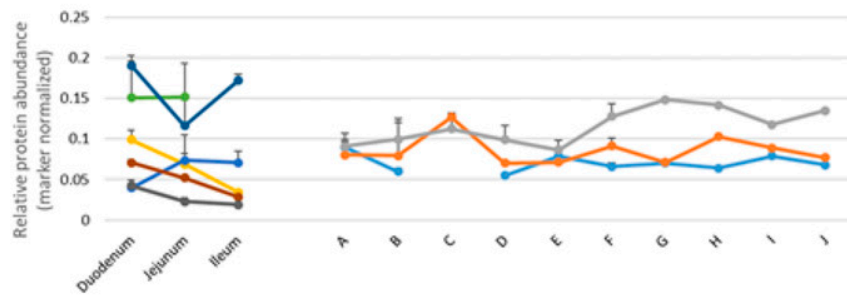

UGT2B7

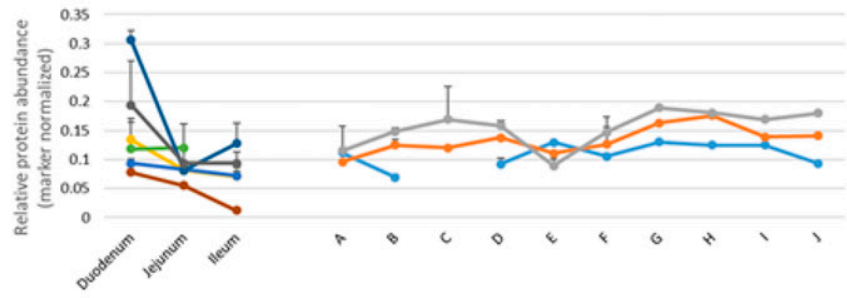

SULT1A1

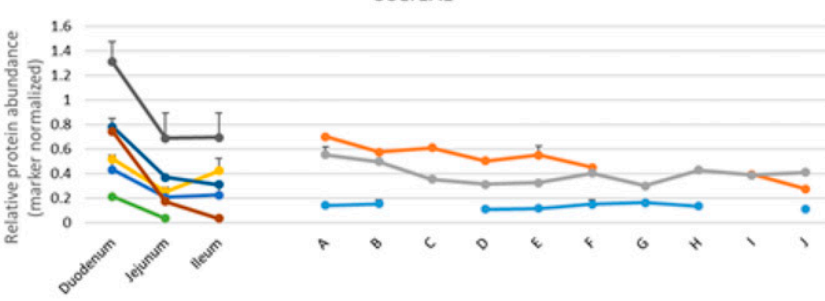

SULT1B1

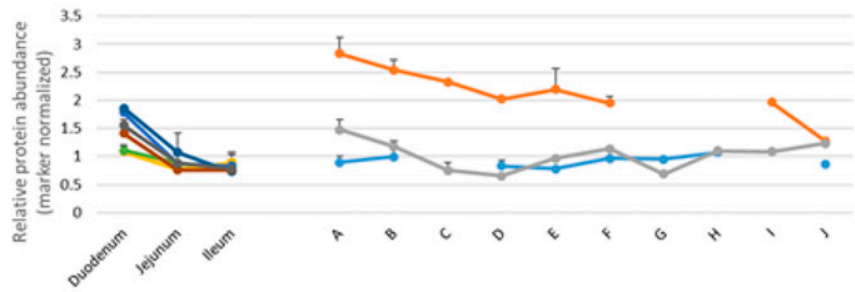

$$
\begin{array}{ll}
-1 & -6023 \\
-2 & -6037 \\
-3 & -6038 \\
-4 & \\
-5 & \\
-6 &
\end{array}
$$

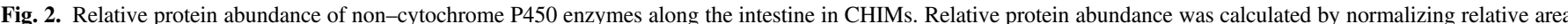

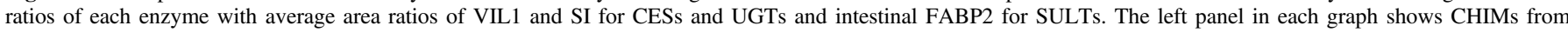

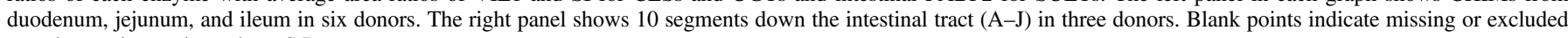
samples, and error bars show S.D. 
A

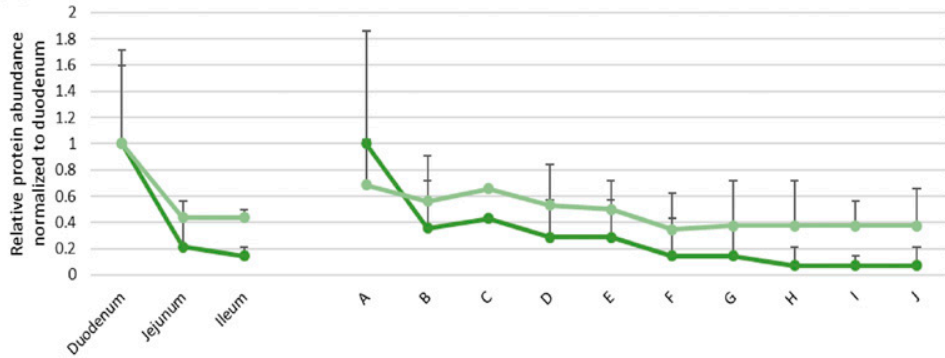

B

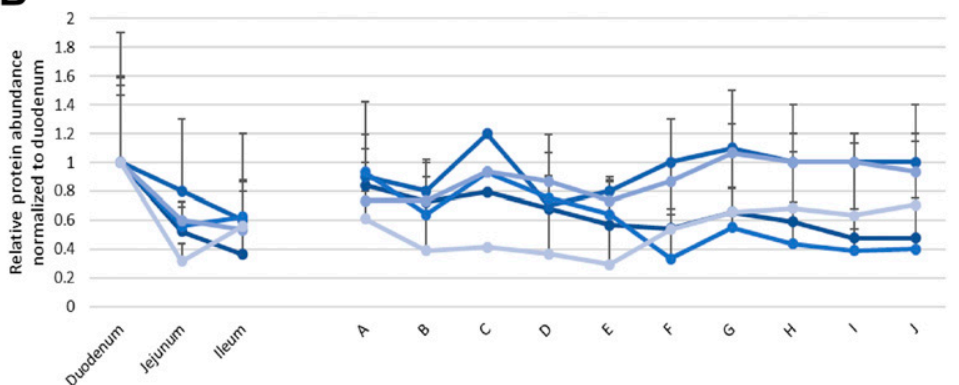

C

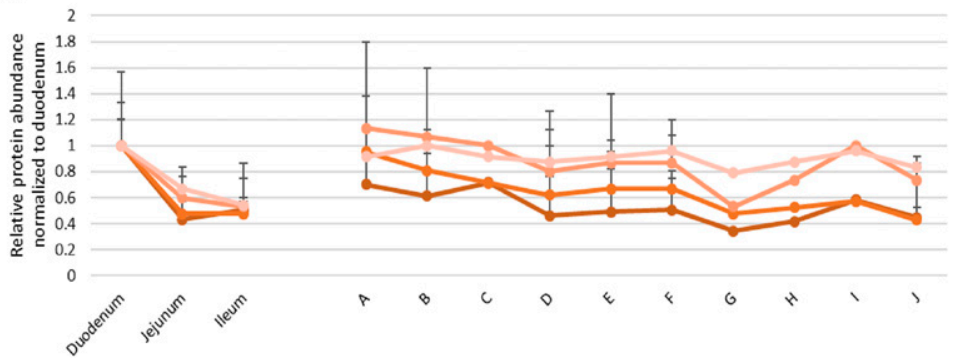

$\rightarrow$ CES1

$\rightarrow$ CES2

\section{$\rightarrow$ SULT1A1 \\ $\rightarrow$ SULT1A3 \\ -SULT1B1 \\ - SULT2A1}

Fig. 3. Average relative abundance of non-cytochrome P450 enzymes along the intestine. Compiled average relative abundance values for CESs (A), UGTs (B), and SULTs (C). Relative values have been standardized to duodenum values as 1 . The left panel in each graph shows CHIMs from duodenum, jejunum, and ileum in six donors. The right panel shows 10 segments down the intestinal tract $(\mathrm{A}-\mathrm{J})$ in three donors. Error bars show S.D

relative metabolite-to-parent ratios (M/P ratios) and absolute protein abundance (Fig. 6). M/P ratios for CES-mediated hydrolysis showed an association with CES1 abundance for CPG (CCA/CPG) and CPT-11 (SN38/CPT-11), with the exception of C6015 with CPG. Secondary
$\mathrm{M} / \mathrm{P}$ ratios for glucuronides also showed a similar association with UGT2B17 abundance for CCA to CAG. Interindividual variability in activity was fairly consistent with corresponding variabilities in enzyme abundance, which exceeded technical variabilities. This indicates the

TABLE 2

Absolute protein quantification mean values (picomoles per milligram protein; S.D. in parentheses) of non-cytochrome P450 enzymes in different segments of human intestine ${ }^{a} \mathrm{~A}-\mathrm{J}$ indicate 10 different intestinal segments from duodenum to ileum.

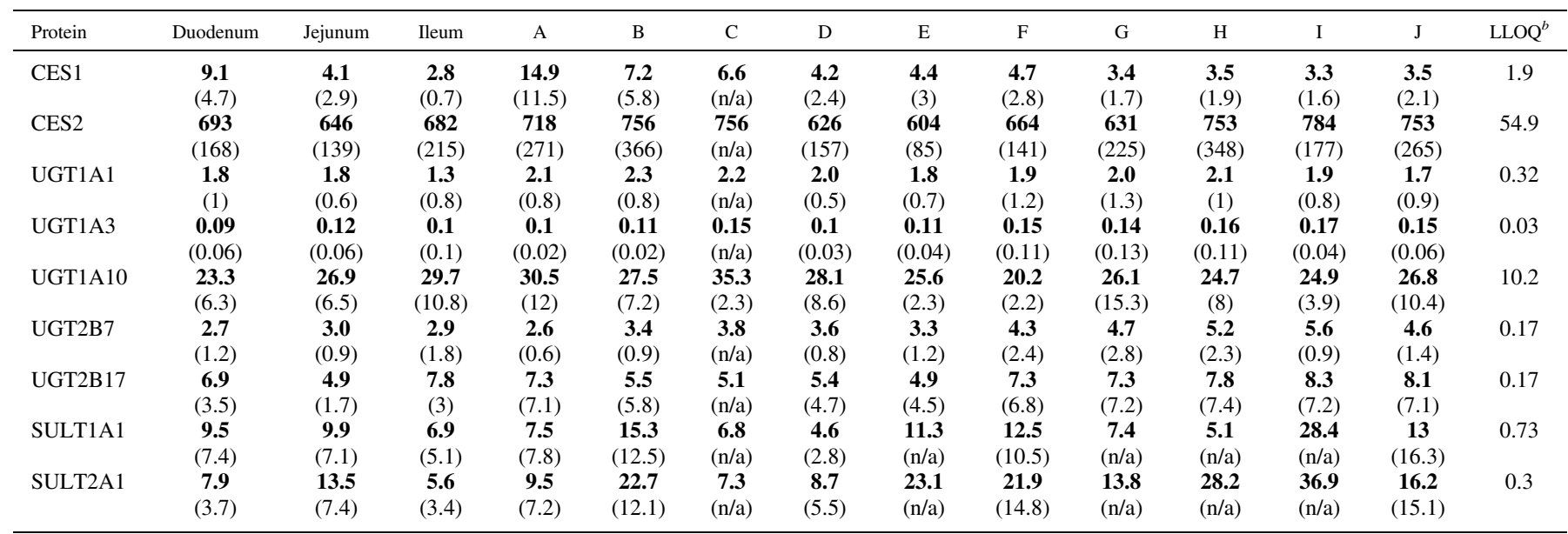

LLOQ, lower limit of quantification.

${ }^{a}$ CES and UGT values are from membrane proteins, and SULTs are from cytosolic proteins.

${ }^{b}$ Picomoles per milligram protein. 

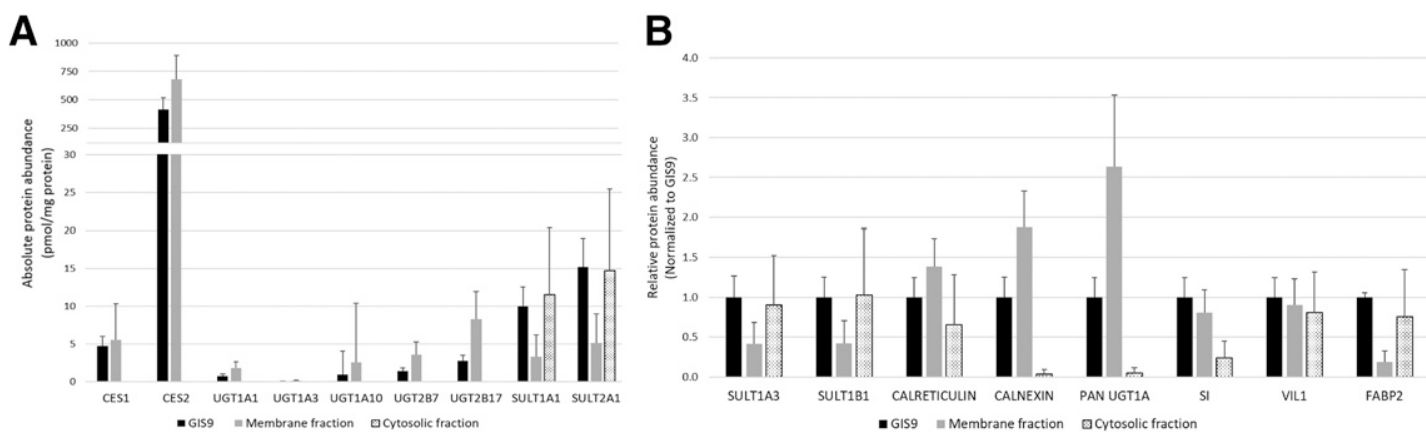

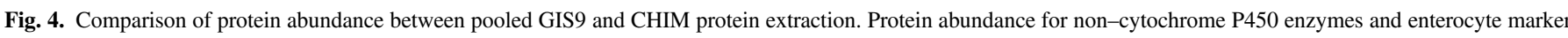

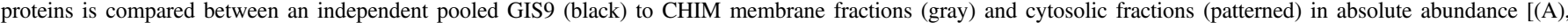

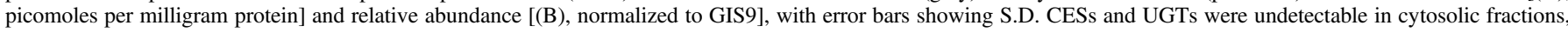
whereas SULTs were detected in both fractions.

importance of using individual donor samples, rather than pooled samples, for predicting the impact of interindividual variability on drug metabolism during drug development for assessing population variability.

\section{Discussion}

Limitations exist in the available in vitro tools for accurate quantitative assessment of intestinal metabolism, and knowledge gaps preclude reliable in vitro-in vivo extrapolation. These limitations stem from the multifunctional nature of the small intestine, which acts as a physical and biochemical protective barrier, as well as an absorptive organ, and comprises a heterogeneous mixture of cell types, the majority being mature enterocytes (Gehart and Clevers, 2019). Intraindividual variability, small sample sizes, and varying technical methods and conditions employed in collection, isolation, or preparation of intestinal mucosa contribute to inconsistent and irreproducible results, with each in vitro model having its own advantages and limitations (Shen et al., 1997; Sawant-Basak et al., 2018). Quantitative proteomic reports on regional distribution of intestinal non-cytochrome P450 enzymes are lacking. Targeted LCMS/MS-based proteomics allows for simultaneous, multiplexed quantification of multiple drug-metabolizing enzymes and transporters, yielding more consistent and reproducible results (Bhatt and Prasad, 2018). Acquired proteomics data can be used to assess technical variabilities due to different preparation methods, as well as biologic variabilities due to multiple cell types. Here, we used quantitative proteomics to investigate regional intestinal abundance of multiple DME proteins and normalization through abundance of enterocyte marker proteins to address technical variability.

Proteomic characterization was performed in two ways. Absolute quantification (picomoles per milligram protein) was done in membrane or cytosolic fractions of CHIM protein extractions, and relative quantification was done using enterocyte marker proteins. Although no head-to-head comparison is available for absolute quantification, values are comparable to published results: slightly lower abundance in CHIM compared with intestinal microsomes (Nakamura et al., 2016; Akazawa et al., 2018) and significantly higher than total tissue abundance (Drozdzik et al., 2017). Importantly, absolute quantification of proteins in the intestinal membrane and cytosolic fractions provides an expression scaling factor that can be applied to in vitro results to predict in vivo first-pass intestinal extraction as well as the contribution of intestinal metabolism to systemic clearance.

Relative quantification using marker normalization was performed to control for technical variabilities, including lot-to-lot variation. Relative normalization resulted in a smoother curve compared with absolute quantification, suggesting that technical variability can significantly affect quantification. Marker proteins such as VIL1, SI, or FABP2 for mature enterocytes may be further applied in in vitro-to-in vivo extrapolations to generate accurate scaling factors. Given the complex anatomy and physiology of the intestine, it would be beneficial to better characterize marker proteins for mature enterocytes as well as for subcellular fractions to provide accurate assessment of enzyme function in vivo. The necessity for marker protein incorporation spans across all in vitro tools and becomes more important as in vitro developments better reflect the multicellular complexity of the intestine, such as
A

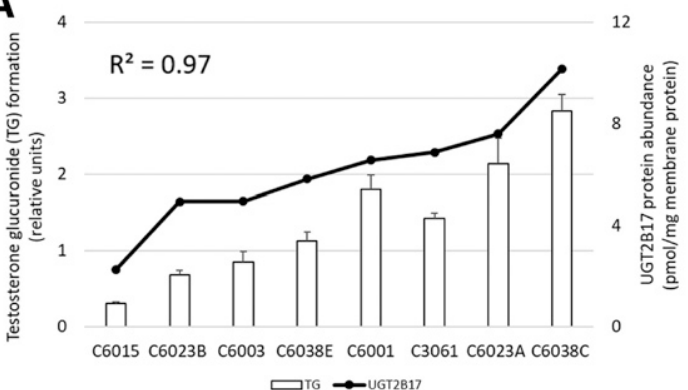

B

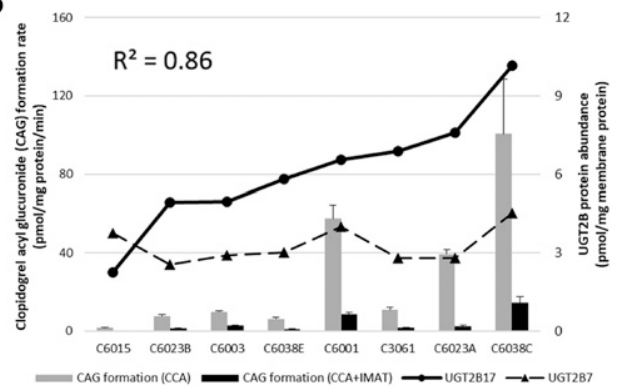

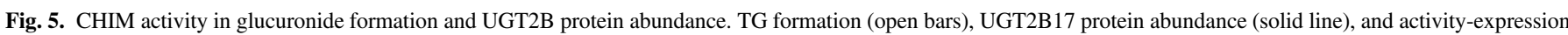

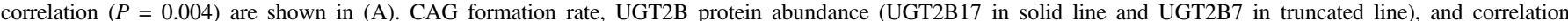

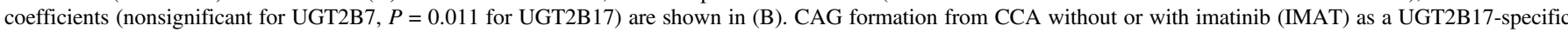

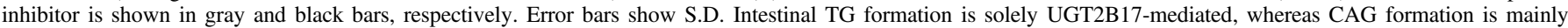
mediated by both UGT2B7 and UGT2B17. 
A

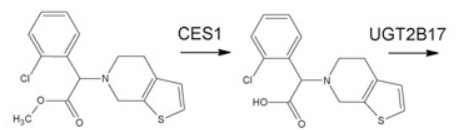

CPG

C

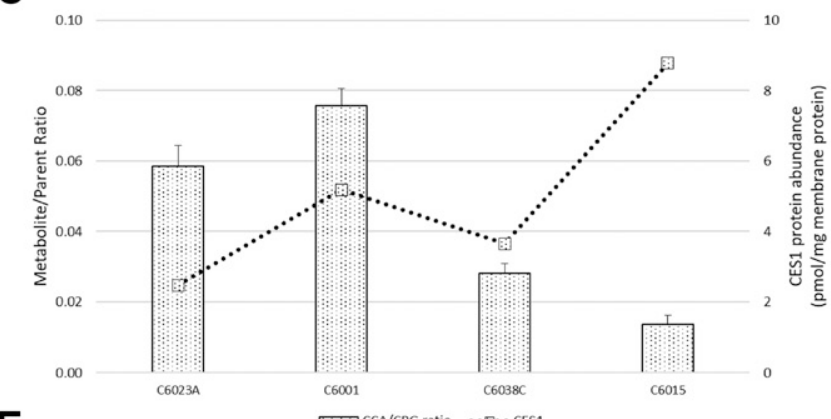

E
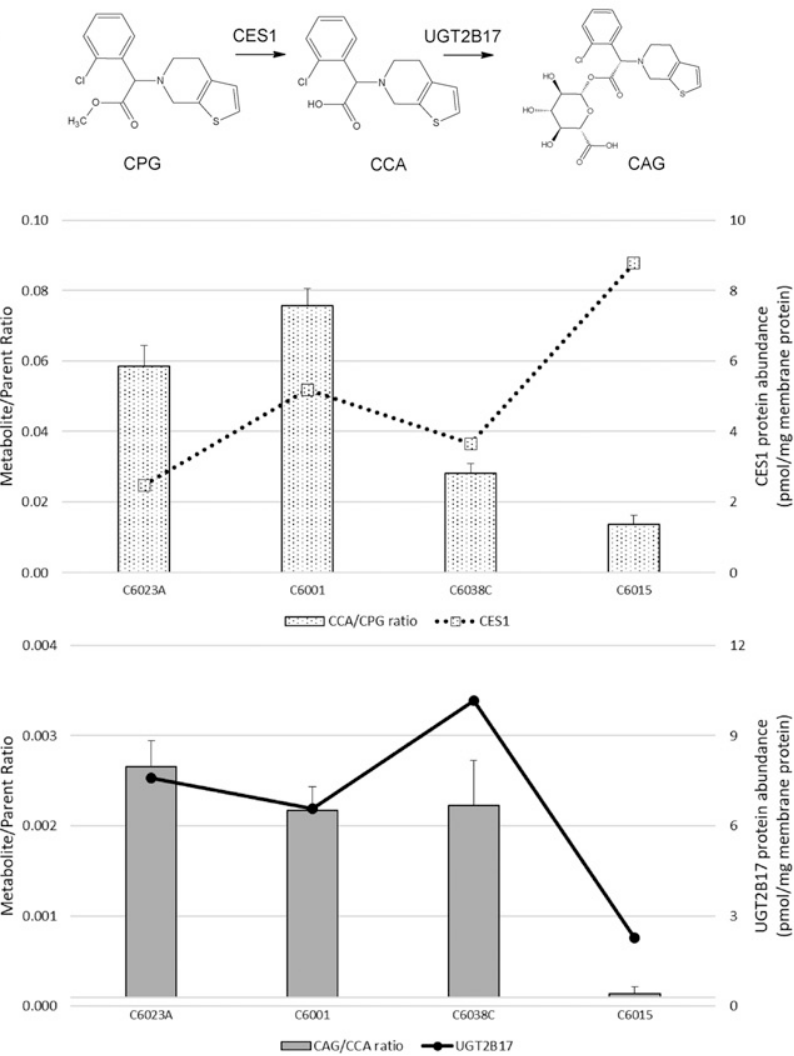

10
B

D
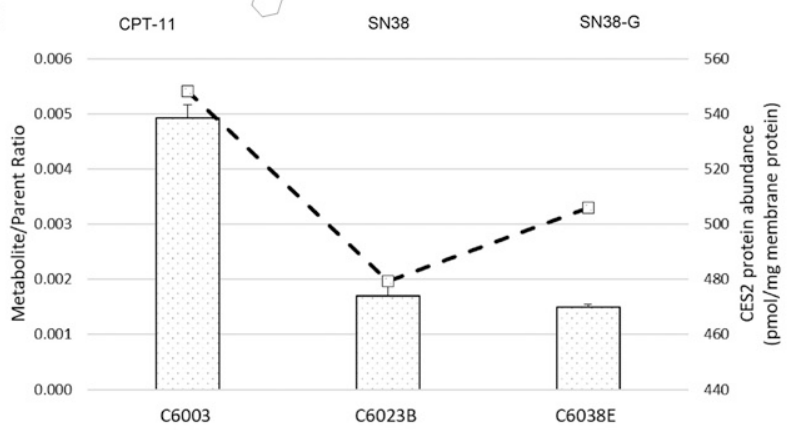

$\mathbf{F}$

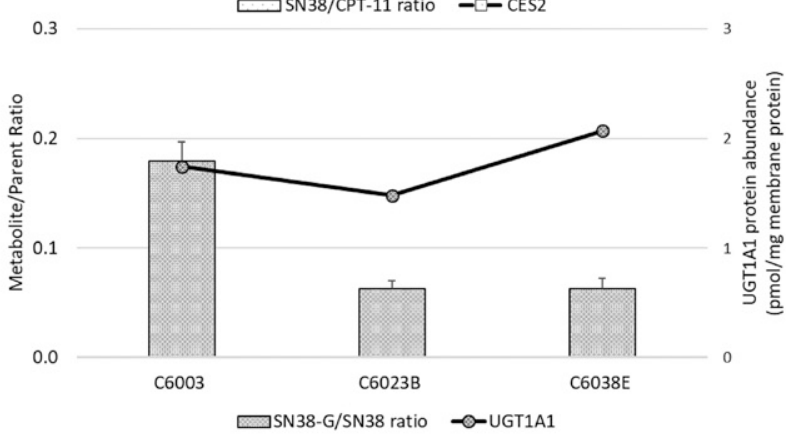

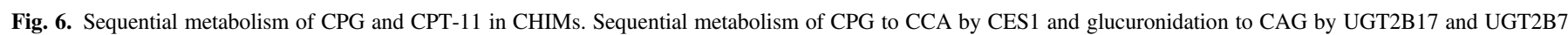

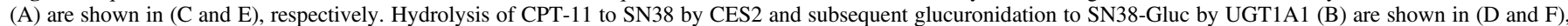
respectively. Metabolite/parent ratios are shown in bars, enzyme abundances are shown in lines, and error bars show S.D.

organoids. In this study, relative abundance of non-cytochrome P450 enzymes, using marker normalization, was higher in duodenum compared with jejunum, whereas absolute abundance was reported to be higher in jejunum compared with duodenum (Drozdzik et al., 2017). This result is likely due to lower abundance of the marker proteins used for normalization, i.e., villin- 1 and sucrase isomaltase, which may be due to lower microvilli and brush-border content per gram of tissue in duodenum. Although utilization of marker proteins is beneficial, this highlights the importance of considering their distribution when planning in vitro-in vivo extrapolations.

Activity assays examined UGT2B-mediated glucuronidation and CES and UGT-mediated sequential metabolism. UGT2B17, although a minor hepatic isoform, is a major isoform in the intestine, and the converse is true for UGT2B7, which is considered the major drugmetabolizing UGT isoform (Williams et al., 2004; Harbourt et al., 2012; Sato et al., 2014). Accordingly, CAG formation is reported to be mediated by UGT2B7 mainly in the liver (50\%-60\%) and with an intestinal contribution of only $12 \%$. UGT2B17's contribution to CAG formation is around $10 \%$ in the liver and increases to $87 \%$ in the intestine (Kahma et al., 2018). Intestinal contribution of UGT2B17 to CAG formation is reproduced in CHIMs, as shown by the strong correlation between CAG formation and UGT2B17 protein abundance. The data highlight the importance of considering individual UGT2B17 abundance when predicting intestinal first-pass metabolism, in which the fraction metabolized may vary widely because of variation from genetic and regulatory factors (Bao et al., 2008; Kaeding et al., 2008; Hu et al., 2014, 2016; Wijayakumara et al., 2015; Bhatt et al., 2018); use of average values will mask the wide range of pharmacokinetic parameters that can be expected for UGT2B17 substrates.
Sequential drug metabolism by CHIMs was also qualitatively examined. Of note, CES1- and UGT2B-mediated clopidogrel metabolism showed an outlier with high CES1 but low CCA/CPG ratio. A possible explanation may be transporter effects; P-glycoprotein, or multidrug resistance protein $1(M D R 1)$, has been shown to influence clopidogrel absorption up to 9-fold in vitro, and clinical associations of lower maximum concentration and exposure for clopidogrel and its active metabolite have been reported with multidrug resistance protein 1 C3435T genotype (Taubert et al., 2006).multidrug resistance protein 1

Some limitations of this study include incomplete protein extraction for cytosolic proteins, resulting in cytosolic proteins being detected in membrane fractions. This may be due to the differential brush-border composition of enterocytes with tight junctions and residual mucus layers, leading to reduced surfactant activity and protein extraction. Although we still saw enrichment of cytosolic proteins, further optimization may be beneficial. Parallel protein quantification in CHIM homogenates or isolated microsomes would have been ideal for crosscomparisons with published studies. In addition, only qualitative activity assessments were made for sequential metabolism of clopidogrel and CPT-11. Further studies with CHIM with higher concentrations may provide more accurate assessments of enzyme activity.

In conclusion, both absolute and relative non-cytochrome P450 proteomic quantifications were performed along the human small intestine using the CHIM model, by utilizing SIL peptides and enterocyte marker proteins. Activity assays validated the proteomic quantifications and also indicate the potential impact of UGT2B17 on intestinal first-pass metabolism as the major intestinal UGT isoform that is highly variable. 


\section{Acknowledgments}

The authors would like to acknowledge Jairam Palamanda, Weixun Wang, Kerry Fillgrove, and Matthew Karasu for their contributions in this work.

\section{Authorship Contributions}

Participated in research design: Zhang, Basit, Li, Fan, Murray, Takahashi,

Khojasteh, Smith, Prasad.

Conducted experiments: Zhang, Wolford.

Contributed new reagents or analytical tools: Li, Prasad.

Performed data analysis: Zhang, Wolford, Basit, Prasad.

Wrote or contributed to the writing of the manuscript: Zhang, Wolford, Basit,

Li, Fan, Murray, Takahashi, Khojasteh, Smith, Thummel, Prasad.

\section{References}

Akazawa T, Uchida Y, Miyauchi E, Tachikawa M, Ohtsuki S, and Terasaki T (2018) High expression of UGT1A1/1A6 in monkey small intestine: comparison of protein expression levels of cytochromes P450, UDP-glucuronosyltransferases, and transporters in small intestine of cynomolgus monkey and human. Mol Pharm 15:127-140.

Bailey DG, Dresser G, and Arnold JMO (2013) Grapefruit-medication interactions: forbidden fruit or avoidable consequences? CMAJ 185:309-316.

Bao B-YY, Chuang B-FF, Wang Q, Sartor O, Balk SP, Brown M, Kantoff PW, and Lee G-SSM (2008) Androgen receptor mediates the expression of UDP-glucuronosyltransferase 2 B15 and B17 genes. Prostate 68:839-848.

Bhatt DK, Basit A, Zhang H, Gaedigk A, Lee S, Claw KG, Mehrotra A, Chaudhry AS, Pearce RE, Gaedigk R, et al. (2018) Hepatic abundance and activity of androgen- and drug-metabolizing enzyme UGT2B17 are associated with genotype, age, and sex. Drug Metab Dispos 46:888-896 DOI: $10.1124 / \mathrm{dmd} .118 .080952$

Bhatt DK, Mehrotra A, Gaedigk A, Chapa R, Basit A, Zhang H, Choudhari P, Boberg M, Pearce RE, Gaedigk R, et al. (2019) Age- and genotype-dependent variability in the protein abundance and activity of six major uridine diphosphate-glucuronosyltransferases in human liver [published correction appears in Clin Pharmacol Ther (2019) 106:891]. Clin Pharmacol Ther 105:131-141 DOI: $10.1002 / \mathrm{cpt} .1109$

Bhatt DK and Prasad B (2018) Critical issues and optimized practices in quantification of protein abundance level to determine interindividual variability in DMET proteins by LC-MS/MS proteomics. Clin Pharmacol Ther 103:619-630 DOI: 10.1002/cpt.819.

Darwich AS, Margolskee A, Pepin X, Aarons L, Galetin A, Rostami-Hodjegan A, Carlert S, Hammarberg M, Hilgendorf C, Johansson P, et al. (2017) IMI - Oral biopharmaceutics tools project - Evaluation of bottom-up PBPK prediction success part 3: identifying gaps in system parameters by analysing in Silico performance across different compound classes. Eur J Pharm Sci 96:626-642.

Deng J, Zhu X, Chen Z, Fan CH, Kwan HS, Wong CH, Shek KY, Zuo Z, and Lam TN (2017) A review of food-drug interactions on oral drug absorption. Drugs 77:1833-1855.

Drozdzik M, Busch D, Lapczuk J, Müller J, Ostrowski M, Kurzawski M, and Oswald S (2018) Protein abundance of clinically relevant drug-metabolizing enzymes in the human liver and intestine: a comparative analysis in paired tissue specimens. Clin Pharmacol Ther 104:515-524 DOI: $10.1002 /$ cpt. 967

Gehart H and Clevers H (2019) Tales from the crypt: new insights into intestinal stem cells. Nat Rev Gastroenterol Hepatol 16:19-34.

Gufford BT, Chen G, Lazarus P, Graf TN, Oberlies NH, and Paine MF (2014) Identification of diet-derived constituents as potent inhibitors of intestinal glucuronidation. Drug Metab Dispos 42:1675-1683.

Harbourt DE, Fallon JK, Ito S, Baba T, Ritter JK, Glish GL, and Smith PC (2012) Quantification of human uridine-diphosphate glucuronosyl transferase $1 \mathrm{~A}$ isoforms in liver, intestine, and kidney using nanobore liquid chromatography-tandem mass spectrometry. Anal Chem 84:98-105.

Hatley OJD, Jones CR, Galetin A, and Rostami-Hodjegan A (2017a) Optimization of intestinal microsomal preparation in the rat: a systematic approach to assess the influence of various methodologies on metabolic activity and scaling factors. Biopharm Drug Dispos 38:187-208.

Hatley OJ, Jones CR, Galetin A, and Rostami-Hodjegan A (2017b) Quantifying gut wall metabolism: methodology matters. Biopharm Drug Dispos 38:155-160.

Ho MD, Ring N, Amaral K, Doshi U, and Li AP (2017) Human enterocytes as an in vitro model for the evaluation of intestinal drug metabolism: characterization of drug-metabolizing enzyme activities of cryopreserved human enterocytes from twenty-four donors. Drug Metab Dispos 45 686-691.

Hodin RA, Shei A, and Meng S (1997) Transcriptional activation of the human villin gene during enterocyte differentiation. J Gastrointest Surg 1:433-438, discussion 438

Hu DG, Meech R, McKinnon RA, and Mackenzie PI (2014) Transcriptional regulation of human UDP-glucuronosyltransferase genes. Drug Metab Rev 46:421-458.

Hu DG, Selth LA, Tarulli GA, Meech R, Wijayakumara D, Chanawong A, Russell R, Caldas C, Robinson JL, Carroll JS, et al. (2016) Androgen and estrogen receptors in breast cancer coregulate human UDP-glucuronosyltransferases 2B15 and 2B17. Cancer Res 76:5881-5893.

Iwao T, Toyota M, Miyagawa Y, Okita H, Kiyokawa N, Akutsu H, Umezawa A, Nagata K, and Matsunaga $\mathrm{T}$ (2014) Differentiation of human induced pluripotent stem cells into functional enterocyte-like cells using a simple method. Drug Metab Pharmacokinet 29:44-51.

Jamei M (2016) Recent advances in development and application of physiologically-based pharmacokinetic (PBPK) models: a transition from academic curiosity to regulatory acceptance. Curr Pharmacol Rep 2:161-169.

Kaeding J, Bouchaert E, Bélanger J, Caron P, Chouinard S, Verreault M, Larouche O, Pelletier G, Staels B, Bélanger A, et al. (2008) Activators of the farnesoid X receptor negatively regulate androgen glucuronidation in human prostate cancer LNCAP cells. Biochem J 410:245-253

Kahma H, Filppula AM, Neuvonen M, Tarkiainen EK, Tornio A, Holmberg MT, Itkonen MK, Finel M, Neuvonen PJ, Niemi M, et al. (2018) Clopidogrel carboxylic acid glucuronidation is mediated mainly by UGT2B7, UGT2B4, and UGT2B17: implications for pharmacogenetics and drug-drug interactions. Drug Metab Dispos 46:141-150.
Kolars JC, Awni WM, Merion RM, and Watkins PB (1991) First-pass metabolism of cyclosporin by the gut. Lancet 338:1488-1490.

Küblbeck J, Hakkarainen JJ, Petsalo A, Vellonen K-S, Tolonen A, Reponen P, Forsberg MM, and Honkakoski P (2016) Genetically modified caco-2 cells with improved cytochrome P450 metabolic capacity. J Pharm Sci 105:941-949.

Li AP, Alam N, Amaral K, Ho MD, Loretz C, Mitchell W, and Yang Q (2018) Cryopreserved human intestinal mucosal epithelium: a novel in vitro experimental system for the evaluation of enteric drug metabolism, cytochrome P450 induction, and enterotoxicity. Drug Metab Dispos 46:1562-1571

Li M, de Graaf IAM, and Groothuis GMM (2016) Precision-cut intestinal slices: alternative mode for drug transport, metabolism, and toxicology research. Expert Opin Drug Metab Toxicol 12: $175-190$

Margolskee A, Darwich AS, Pepin X, Aarons L, Galetin A, Rostami-Hodjegan A, Carlert S, Hammarberg M, Hilgendorf C, Johansson P, et al. (2017a) IMI - Oral biopharmaceutics tools project - evaluation of bottom-up PBPK prediction success part 2: an introduction to the simulation exercise and overview of results. Eur J Pharm Sci 96:610-625.

Margolskee A, Darwich AS, Pepin X, Pathak SM, Bolger MB, Aarons L, Rostami-Hodjegan A, Angstenberger J, Graf F, Laplanche L, et al. (2017b) IMI - oral biopharmaceutics tools project evaluation of bottom-up PBPK prediction success part 1: characterisation of the OrBiTo database of compounds. Eur J Pharm Sci 96:598-609.

Nakamura K, Hirayama-Kurogi M, Ito S, Kuno T, Yoneyama T, Obuchi W, Terasaki T, and Ohtsuki S (2016) Large-scale multiplex absolute protein quantification of drug-metabolizing enzymes and transporters in human intestine, liver, and kidney microsomes by SWATH-MS comparison with MRM/SRM and HR-MRM/PRM. Proteomics 16:2106-2117.

Paine MF, Hart HL, Ludington SS, Haining RL, Rettie AE, and Zeldin DC (2006) The human intestinal cytochrome P450 "pie". Drug Metab Dispos 34:880-886.

Paine MF, Shen DD, Kunze KL, Perkins JD, Marsh CL, McVicar JP, Barr DM, Gillies BS, and Thummel KE (1996) First-pass metabolism of midazolam by the human intestine. Clin Pharmacol Ther 60:14-24.

Peters SA, Jones CR, Ungell A-L, and Hatley OJD (2016) Predicting drug extraction in the human gut wall: assessing contributions from drug metabolizing enzymes and transporter proteins using preclinical models. Clin Pharmacokinet 55:673-696.

Piton G and Capellier G (2016) Biomarkers of gut barrier failure in the ICU. Curr Opin Crit Care 22:152-160.

Prasad B, Vrana M, Mehrotra A, Johnson K, and Bhatt DK (2017) The promises of quantitative proteomics in precision medicine. J Pharm Sci 106:738-744.

Rostami-Hodjegan A (2012) Physiologically based pharmacokinetics joined with in vitro-in vivo extrapolation of ADME: a marriage under the arch of systems pharmacology. Clin Pharmacol Ther 92:50-61.

Rostami-Hodjegan A, Tamai I, and Pang KS (2017) Revisiting the role of gut wall in the fate of orally administered drugs: why now and to what effect? Biopharm Drug Dispos 38:87-93.

Sato Y, Nagata M, Tetsuka K, Tamura K, Miyashita A, Kawamura A, and Usui T (2014) Optimized methods for targeted peptide-based quantification of human uridine $5^{\prime}$-diphosphate-glucuronosyltransferases in biological specimens using liquid chromatography-tandem mass spectrometry. Drug Metab Dispos 42:885-889.

Sawant-Basak A, Rodrigues AD, Lech M, Doyonnas R, Kasaian M, Prasad B, and Tsamandouras N (2018) Physiologically relevant, humanized intestinal systems to study metabolism and transport of small molecule therapeutics. Drug Metab Dispos 46:1581-1587.

Shen DD, Kunze KL, and Thummel KE (1997) Enzyme-catalyzed processes of first-pass hepatic and intestinal drug extraction. Adv Drug Deliv Rev 27:99-127.

Takahashi RH, Choo EF, Ma S, Wong S, Halladay J, Deng Y, Rooney I, Gates M, Hop CECA, Khojasteh SC, et al. (2016) Absorption, metabolism, excretion, and the contribution of intestinal metabolism to the oral disposition of [14C]cobimetinib, a MEK inhibitor, in humans. Drug Metab Dispos 44:28-39.

Taubert D, von Beckerath N, Grimberg G, Lazar A, Jung N, Goeser T, Kastrati A, Schömig A, and Schömig E (2006) Impact of P-glycoprotein on clopidogrel absorption. Clin Pharmacol Ther 80:486-501.

Thummel KE (2007) Gut instincts: CYP3A4 and intestinal drug metabolism. J Clin Invest 117: 3173-3176.

Vrana M, Whittington D, Nautiyal V, and Prasad B (2017) Database of optimized proteomic quantitative methods for human drug disposition-related proteins for applications in physiologically based pharmacokinetic modeling. CPT Pharmacometrics Syst Pharmacol 6:267-276.

Wijayakumara DD, Hu DG, Meech R, McKinnon RA, and Mackenzie PI (2015) Regulation of human UGT2B15 and UGT2B17 by miR-376c in prostate cancer cell lines. J Pharmacol Exp Ther 354:417-425.

Williams JA, Hyland R, Jones BC, Smith DA, Hurst S, Goosen TC, Peterkin V, Koup JR, and Ball SE (2004) Drug-drug interactions for UDP-glucuronosyltransferase substrates: a pharmacokinetic explanation for typically observed low exposure (AUCi/AUC) ratios. Drug Metab Dispos 32:1201-1208

Wu B, Kulkarni K, Basu S, Zhang S, and Hu M (2011) First-pass metabolism via UDP-glucuronosyltransferase: a barrier to oral bioavailability of phenolics. J Pharm Sci 100:3655-3681.

Yamaura Y, Chapron BD, Wang Z, Himmelfarb J, and Thummel KE (2016) Functional comparison of human colonic carcinoma cell lines and primary small intestinal epithelial cells for investigations of intestinal drug permeability and first-pass metabolism. Drug Metab Dispos 44: 329-335.

Yeo KR, Jamei M, and Rostami-Hodjegan A (2013) Predicting drug-drug interactions: application of physiologically based pharmacokinetic models under a systems biology approach. Expert Rev Clin Pharmacol 6:143-157.

Zhang H, Basit A, Busch D, Yabut K, Bhatt DK, Drozdzik M, Ostrowski M, Li A, Collins C, Oswald S, et al. (2018) Quantitative characterization of UDP-glucuronosyltransferase 2B17 in human liver and intestine and its role in testosterone first-pass metabolism. Biochem Pharmaco 156:32-42.

Address correspondence to: Bhagwat Prasad, Department of Pharmaceutical Sciences, Washington State University, 412 E Spokane Falls Blvd., Spokane, WA 99202. E-mail: bhagwat.prasad@wsu.edu 